\title{
Movimientos anormales en un paciente con encefalitis límbica: reporte de caso y revisión de la literatura
} Abnormal movements in a patient with limbic
encephalitis: case report and literature review

\author{
Nadia A Gandarilla-Martínez, Braulia A Martínez-Díaz, Luis Espinosa-Aguilar, \\ Javier Zúñiga-Varga, A Iván Smirnov-Castro, Miguel A Collado-Ortiz
}

Centro Médico ABC Campus Santa Fe. Centro de Neurología, Ortopedia y Rehabilitación.

\section{RESUMEN}

La encefalitis es un proceso inflamatorio del parénquima cerebral que puede ser de causa infecciosa o autoinmune. Clínicamente se presenta con cefalea, fiebre, alteración en el estado mental, déficit neurológico focal y crisis convulsivas. El patrón de déficit neurológico es útil en el abordaje etiológico. Presentamos el caso de un paciente de 32 años quien cursó con encefalitis límbica, aunque con afectación temporal medial unilateral. Durante la evolución desarrolló inestabilidad autonómica, discinesias faciales, corea, mioclono y temblor. El estudio microbiológico fue negativo para virus (virus herpes tipo 1), bacterias y hongos. Los anticuerpos contra N-metil-D-aspartato y los anticuerpos intraneuronales en líquido cefalorraquídeo fueron negativos. Recibió tratamiento con antibiótico y antiviral, con lo cual experimentó mejoría gradual de los síntomas en un periodo de dos semanas sin evidencia de recaídas ni necesidad de tratamiento inmunomodulador. Aunque no se logró identificar un agente causal, consideramos que el padecimiento fue ocasionado por un proceso infeccioso debido a su carácter autolimitado y la buena respuesta a antimicrobianos.

Palabras clave: Encefalitis infecciosa, encefalitis autoinmune, movimientos anormales, disfunción autonómica.
ABSTRACT

Encephalitis is an inflammatory process of the brain parenchyma that can be either infectious or autoimmune. It presents with headache, fever, altered mental status, focal neurological deficits and seizures. The pattern of neurological involvement is useful in the clinical approach. We present the case of a 32-year-old male who presented with limbic encephalitis but unilateral temporal involvement. During the clinical course he developed autonomic instability, facial dyskinesias, chorea, myoclonus and tremor. The microbiological study was negative for viruses (including herpes virus type 1), bacteria and fungi. Antibodies against $\mathrm{N}$-methyl-D-aspartate and intraneuronal antibodies in cerebrospinal fluid were negative. He was treated with antibiotics and antivirals with gradual improvement of symptoms over a period of two weeks without evidence of relapse and without the need for immunomodulatory treatment. Although it was not possible to identify a causative agent, we consider that the patient's clinical picture was secondary to an infectious process due to its self-limited nature and the good response to antimicrobials.

Keywords: Infectious encephalitis, autoimmune encephalitis, abnormal movement, autonomic dysfunction.

Abreviaturas: $\mathrm{ADC}=$ Coeficiente de difusión aparente, $\mathrm{AMPA}=\alpha$-amino-3-hidroxi-5-metil-4-isoxazol-propionato, Cho $=$ Colina, $\mathrm{CRMP5}=\mathrm{Collapsin}$ response mediator protein 5, GABA = Ácido gamma aminobutírico, MoCA $=$ Montreal cognitive assessment, $\mathrm{NAA}=\mathrm{N}$-acetil-aspartato, NMDA $=\mathrm{N}$-metil$\mathrm{D}$-aspartato, $\mathrm{PCR}=$ Reacción en cadena de polimerasa, SNC = Sistema nervioso central, TCREM = Trastorno de la conducta del sueño REM . 


\section{INTRODUCCIÓN}

La encefalitis es una inflamación del parénquima cerebral que puede tener una etiología infecciosa o autoinmune. En la mayoría de los casos se presenta con un cuadro de instauración aguda/subaguda de alteración en el estado mental (disminución o alteración en el nivel de conciencia, letargia y/o alteración de la conducta), fiebre, déficit neurológico focal y crisis epilépticas. El cuadro clínico puede acompañarse de anormalidad del líquido cefalorraquídeo (LCR) con $\geq 5$ leucocitos $/ \mathrm{mm}^{3}$, hiperintensidades en resonancia magnética cerebral (RM) observadas en T2/ FLAIR restringidas a uno o ambos lóbulos temporales o que involucren la sustancia gris, blanca o ambas, (compatibles con desmielinización o inflamación) y/o alteraciones electroencefalográficas (enlentecimiento focal o difuso, actividad desorganizada y/o actividad epiléptica). ${ }^{1}$ El patrón de déficit neurológico puede sugerir una etiología específica. ${ }^{2}$

\section{CASO CLÍNICO}

Presentamos el caso de un hombre de 32 años, sin antecedentes de relevancia, quien acudió a urgencias de nuestra institución por cuadro de náusea y vómito persistentes. Durante su traslado presentó una crisis convulsiva tónica clónica generalizada y un segundo evento 30 minutos después (en el servicio de urgencias). Se administraron 5 mg de diazepam y 1 gramo de levetiracetam intravenosos, posteriormente continuó con levetiracetam 1.5 gramos vía oral cada 12 horas. Tras recuperar el estado de alerta se mantuvo con agitación psicomotriz y confusión el resto del día. El interrogatorio indirecto reveló que la semana previa a su ingreso, había tenido cefalea holocraneana y fiebre. La prueba de PCR ambulatoria e intrahospitalaria para detección de SARS-CoV-2 fue negativa.

En la evaluación inicial se reportó TA de 128/60 mmHg, FC 113 lpm, FR $16 \mathrm{rpm}$ y temperatura $36.6^{\circ} \mathrm{C}$. Exploración general sólo con xerostomía. Neurológicamente estaba despierto, desorientado, mostraba falta de atención, con lenguaje incoherente. Nervios del cráneo sin alteraciones. Movilización simétrica de las cuatro extremidades, reflejos de estiramiento muscular $2+$ generalizados, respuesta plantar flexora bilateral. Sensibilidad aparentemente intacta. Sin alteración cerebelosa. Signos meníngeos no presentes.

Los estudios de laboratorio mostraron acidosis metabólica ( $\mathrm{pH}$ 6.92, $\mathrm{HCO}_{3} 8.4$ lactato 22), marcadores inflamatorios
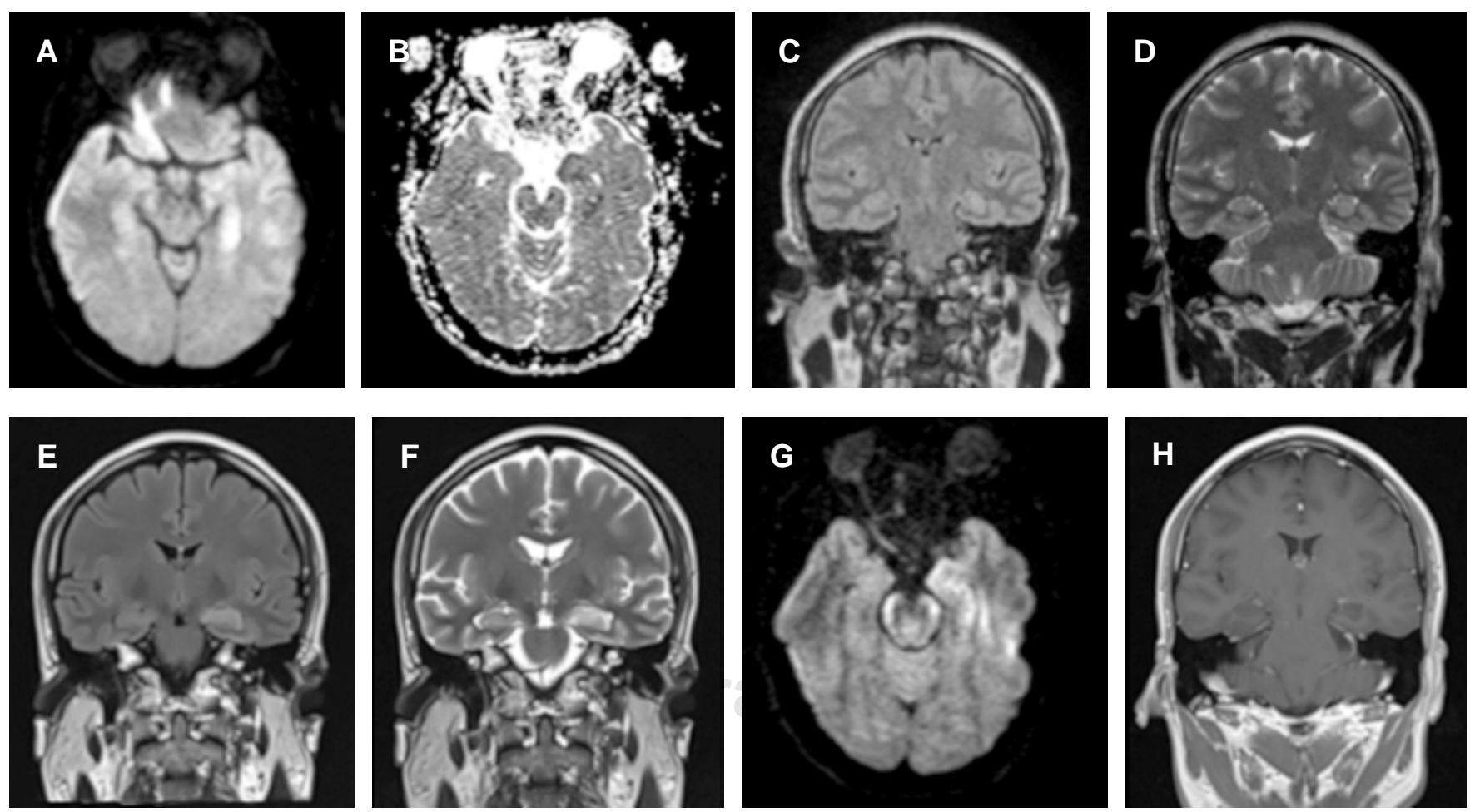

Figura 1: (A-B) Resonancia magnética de encéfalo inicial muestra restricción a la difusión del hipocampo izquierdo y la corteza del giro parahipocampal homolateral que se corrobora en ADC. (C-D) En el plano coronal de las secuencias FLAIR y T2 se muestra redondeamiento a nivel del cuerpo del hipocampo izquierdo con escasa hiperseñal. (E-F) Resonancia magnética de control (dos semanas después de la primera) donde se observa en cortes coronales T2 y FLAIR persistencia de la hiperintensidad en el cuerpo y cola del hipocampo izquierdo. (G) Restricción a la difusión. (H) Ausencia de captación de medio de contraste. 

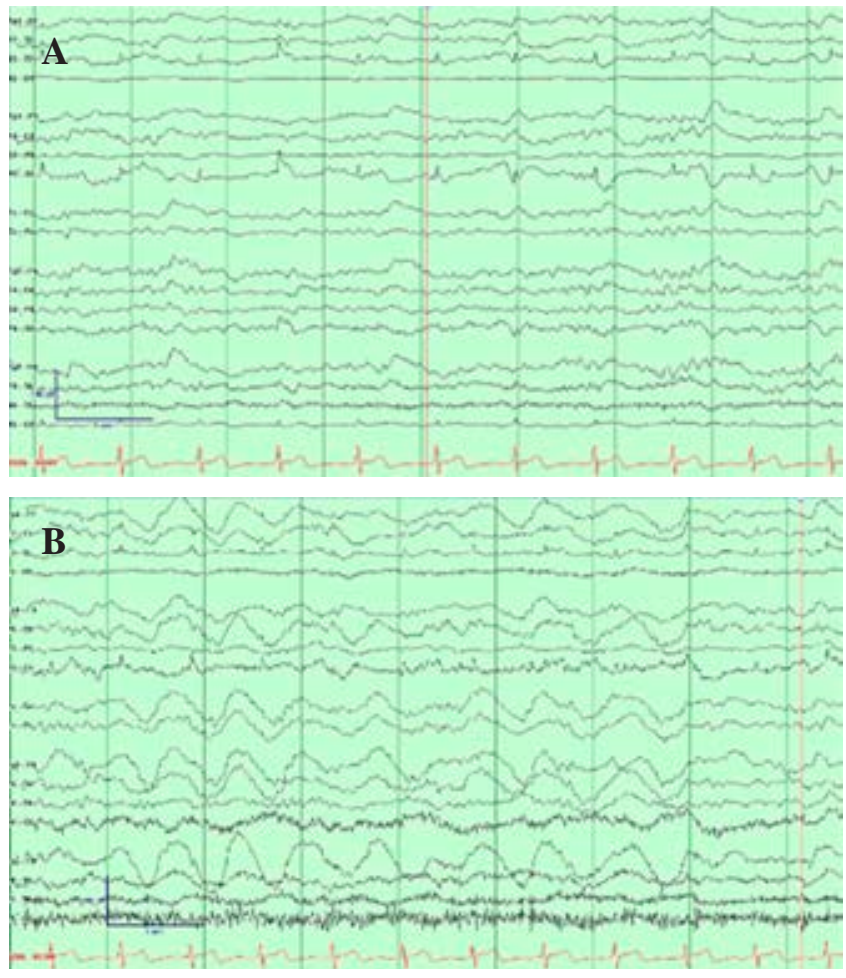

Figura 2: (A) Electroencefalograma digital donde se observa actividad theta generalizada entremezclada con actividad rápida por efecto farmacológico. (B) Se observa actividad delta de gran amplitud en regiones frontales, rítmica de manera intermitente (FIRDAS) y algunas ondas agudas en región temporal anterior izquierda.

elevados (leucocitosis 19,600, proteína C reactiva 12.4, procalcitonina 2.23), elevación de transaminasas (ALT 150, AST 95.4, GGT 269), disfunción renal (creatinina 5.72, BUN 41) y rabdomiólisis (CK 3445, CK-MB 50.7, troponina 11, mioglobina 762). La RM cerebral mostró restricción a la difusión en hipocampo izquierdo y corteza del giro parahipocampal homolateral que se corroboró en ADC (Figura 1A-D). De la punción lumbar se obtuvo líquido de aspecto turbio, con presión de apertura de $300 \mathrm{cmH}_{2} \mathrm{O}$, citoquímico con pleocitosis linfocitaria (células 189, 96\% mononucleares), proteínas $21 \mathrm{mg} / \mathrm{dL}$, glucosa 91 $\mathrm{mg} / \mathrm{dL}$ ). El electroencefalograma digital mostró actividad theta generalizada entremezclada con actividad rápida por efecto farmacológico (diazepam), ondas agudas en región temporal anterior izquierda, actividad delta de gran amplitud en regiones frontales, rítmica e intermitente (FIRDAS), y frecuentes ondas lentas de morfología angulada periódicas generalizadas con ocasional lateralización hacia ambas regiones temporales ( $F i$ gura $2 A$ y B). Por la sospecha de encefalitis infecciosa se inició cobertura empírica con ceftriaxona, vancomicina, ampicilina, aciclovir y dexametasona.

Durante los primeros días de estancia en el servicio de terapia intermedia se mantuvo alerta, parcialmente orientado con algunas fallas en memoria retrógrada, sin crisis convulsivas. Cognitivamente se documentó alteración en memoria, cálculo y orientación por prueba de MoCA (Montreal cognitive assessment), obtuvo puntaje de 22.

En los días subsecuentes desarrolló lesión renal aguda, por lo que requirió una sesión de hemodiafiltración venovenosa continua. Desarrolló inestabilidad autonómica (IA) caracterizada por variabilidad en la tensión arterial y en la frecuencia cardiaca, requiriendo manejo con nitroglicerina por hipertensión arterial de difícil control. A partir de entonces, se observaron en el paciente movimientos anormales caracterizados por temblor de la voz, temblor cefálico en negación, temblor postural de alta frecuencia en extremidades superiores, discinesias faciales (parpadeo excesivo, movimiento clónico en región frontal), movimientos coreoatetósicos frecuentes en las cuatro extremidades de predominio en las inferiores, mioclonías espontáneas intermitentes en extremidades inferiores. Se inició amantadina 100 mg cada ocho horas para el control de las discinesias y dexmedetomidina, debido a que cursó con episodio de agitación psicomotriz y confusión que remitió después de 24 horas. Posterior a la suspensión de dexmedetomidina se inició quetiapina 50 mg y lorazepam 2 mg cada ocho horas; se sustituyó levetiracetam por lacosamida 100 mg cada 12 horas.

Debido al desarrollo de IA y de movimientos anormales se consideró la posibilidad de una encefalitis autoinmune, por lo que se determinaron anticuerpos antirreceptor de NMDA, anticuerpos intraneuronales (anti-Hu, anti-Yo, anti-Ri, antiamfifisina, anti-CRMP5) y bandas oligoclonales en LCR, los cuales fueron negativos. No se exploraron otros anticuerpos contra antígenos de superficie y proteínas sinápticas (antirreceptor AMPA, antirreceptor GABAB, antirreceptor LGl1, antirreceptor CASPR-2). El estudio microbiológico del LCR fue negativo para bacterias, hongos, micobacterias y para los virus herpes tipo 1 (HSV 1), herpes tipo 2 (HSV 2), varicela zóster (VZV), citomegalovirus, Epstein-Barr virus, Coxsackie A, Coxsackie B, Echovirus y virus West Nile (VWN). La serología para VIH y el VDRL sérico fueron negativos. Otros estudios para investigar enfermedades sistémicas fueron negativos (perfil tiroideo, anticuerpos antinucleares, anticardiolipinas, marcadores tumorales). La punción lumbar de control, realizada el sexto día de tratamiento antimicrobiano, mostró disminución de la pleocitosis (células 50, mononucleares 100\%, proteínas 22.4 $\mathrm{mg} / \mathrm{dL}$, glucosa $66 \mathrm{mg} / \mathrm{dL}$ ). La RM cerebral de control, con dos semanas de diferencia de la primera, demostró persistencia de la hiperintensidad en cuerpo y cola del hipocampo izquierdo en T2/FLAIR y de la restricción a la difusión en la misma zona, pero sin reforzamiento tras la administración de gadolinio (Figura 1E-H).

Posterior al reporte microbiológico continuó tratamiento sólo con aciclovir hasta completar 14 días. El paciente evolucionó favorablemente con resolución de la inestabilidad autonómica y de los episodios de agitación psicomotriz. Los movimientos anormales (principalmente 
las mioclonías y discinesias) disminuyeron de manera gradual. Al egreso hospitalario sólo se documentó discreto temblor postural de extremidades superiores y de la voz. Se mantuvo tratamiento ambulatorio con lorazepam 2 mg cada ocho horas, amantadina 100 mg cada 12 horas, quetiapina $50 \mathrm{mg}$ diarios y lacosamida $100 \mathrm{mg}$ cada 12 horas, los cuales se fueron retirando de manera gradual a excepción de lacosamida. Hasta el día de hoy el paciente se encuentra sin déficit neurológico, ocasionalmente presenta crisis focales complejas.

\section{DISCUSIÓN}

Presentamos el caso de un paciente que mostró un cuadro clásico de encefalitis y que durante la evolución clínica desarrolló inestabilidad autonómica y movimientos anormales (mioclonías, temblor y discinesias). La presentación clínica, la evidencia radiológica y electroencefalográfica de afectación de la región medial temporal izquierda nos permitió dirigir el abordaje para investigar causas de encefalitis límbica (EL). La EL se caracteriza por alteraciones en la memoria, cambio en la conducta y manifestaciones psiquiátricas asociadas con anormalidades unilaterales o bilaterales en T2/FLAIR restringidas a la región medial de los lóbulos temporales y a la presencia de actividad disfuncional o epiléptica en la misma región. ${ }^{3}$ El síndrome ha sido descrito en asociación con anticuerpos antineuronales dirigidos contra antígenos intracelulares y/o de superficie, que ocasionalmente se desencadenan por la presencia de un tumor fuera del SNC (encefalitis paraneoplásica). ${ }^{4}$ La EL no es exclusivamente autoinmune, ya que puede observarse en encefalitis causadas por HSV $1,{ }^{5} \mathrm{VZV}$, virus herpes tipo 6 (HSV 6) y excepcionalmente en neurosífilis. ${ }^{6}$ Otros diagnósticos diferenciales de EL con afectación unilateral son cambios postictales temporales y la presencia de un tumor glial. Zoccarato y colaboradores realizaron y analizaron los hallazgos radiológicos en pacientes con EL autoinmune y en pacientes con gliomas temporales. Identificaron que una adecuada diferenciación entre la sustancia gris y blanca se encontraba fuertemente asociada con EL y alterada en la mayoría de casos con gliomas (91\% vs. $17 \% \mathrm{p}<0.001)^{7}$

La posibilidad de que los hallazgos radiológicos fueran cambios postictales se descartó, ya que persistían en la IRM de control. Los hallazgos tampoco fueron sugerentes de una neoplasia temporal. A pesar del abordaje exhaustivo no se identificó un agente infeccioso causal ni tampoco la presencia de un anticuerpo antineuronal asociado. Desde nuestro punto de vista el cuadro clínico es sugestivo de infección por HSV-1 y aunque el PCR fue negativo no se puede excluir totalmente esta posibilidad, ya que existen varios reportes en la literatura de falsos negativos cuando el PCR se determina durante los primeros días de instauración de los síntomas. ${ }^{8}$
El desarrollo de IA y de movimientos anormales nos llevaron a considerar otros diagnósticos diferenciales de encefalitis por HSV 1 tanto infecciosos como autoinmunes. La IA en encefalitis se ha reportado cuando existe una afectación del tallo cerebral como en la romboencefalitis que puede ser ocasionada por diversos virus (enterovirus $71, \mathrm{VWN}$, virus de la encefalitis japonesa, Lyssavirus), bacterias (Brucella, Borrelia, M. tuberculosis, toxoplasma) y en el contexto de un síndrome paraneoplásico. Además de la IA puede haber mioclonías y neuropatías craneales. ${ }^{2}$ Para el diagnóstico se requiere evidencia radiológica de afectación del tallo cerebral (no presente en nuestro paciente). La IA a su vez es un dato cardinal en la encefalitis por anticuerpos antirreceptor de NMDA. ${ }^{9}$

El desarrollo de trastornos del movimiento (TM) en el contexto de un paciente con encefalitis (sin alteración estructural de los núcleos de la base) sugiere un trasfondo inmunológico, pero no son exclusivos de encefalitis autoinmunes y pueden manifestarse en encefalitis infecciosas. Se ha propuesto en los TM parainfecciosos, como mecanismo fisiopatogénico, el desarrollo de una respuesta inmunológica dirigida contra antígenos neuronales o gliales propios, desencadenada por un mimetismo molecular entre antígenos infecciosos y neurales. ${ }^{10}$ Resumimos los TM reportados en algunas de las encefalitis infecciosas y autoinmunes más comunes (Tabla 1). ${ }^{11-13}$

A pesar de no haber encontrado una etiología específica sostenemos que la encefalitis en nuestro paciente tuvo un comportamiento infeccioso (muy probablemente por HSV-1) debido a la excelente respuesta con el tratamiento antimicrobiano y a la resolución de la mayor parte de los síntomas tras un periodo de dos semanas, sin necesidad de tratamiento inmunomodulador ni evidencia de recaídas durante la evolución.

El caso es interesante y representativo del abordaje diagnóstico de un paciente con encefalitis límbica, inestabilidad autonómica y movimiento anormales.

\section{CONCLUSIÓN}

En las últimas décadas se han descrito nuevas causas de encefalitis infecciosas, parainfecciosas o postinfecciosas y autoinmunes. A pesar de esto la dificultad para encontrar la causa específica en la mayoría de los pacientes que la padecen continúa siendo una constante. Es por ello que el abordaje debe orientarse en razón de las manifestaciones clínicas específicas o atípicas, la región del parénquima involucrada, los hallazgos radiológicos y marcadores que sugieran autoinmunidad. Reducir el número de diagnósticos diferenciales contribuye al inicio temprano del tratamiento y de este modo a influir positivamente en el desenlace clínico y a evitar estudios y tratamientos innecesarios. 
Tabla 1: Trastornos del movimiento asociados a encefalitis autoinmunes e infecciosas.

\begin{tabular}{|c|c|c|c|}
\hline Causa & Trastornos del movimiento & Otros datos clínicos & Etiología \\
\hline Encefalitis japonesa & $\begin{array}{l}\text { Parkinsonismo, distonía, corea, } \\
\text { atetosis, mioclono. }\end{array}$ & Parálisis flácida & $\begin{array}{l}\text { Parainfecciosa } \\
\text { Alteración de NB }\end{array}$ \\
\hline Encefalitis por VWN & $\begin{array}{l}\text { Temblor, opsoclono-mioclono, } \\
\text { parkinsonismo, ataxia, corea }\end{array}$ & Confusión, crisis epilépticas & Postinfecciosa \\
\hline Encefalitis antirreceptor NMDA & $\begin{array}{l}\text { Corea, estereotipias, catatonia, } \\
\text { distonía, ataxia cerebelar }\end{array}$ & $\begin{array}{l}\text { Alucinaciones, disautonomía, } \\
\text { hipoventilación central }\end{array}$ & $\begin{array}{l}\text { Autoinmune } \\
\text { Paraneoplásica 58\% }\end{array}$ \\
\hline $\begin{array}{l}\text { Encefalitis antirreceptor de } \\
\text { GABA }_{B}\end{array}$ & $\begin{array}{l}\text { Ataxia, opsoclono, corea, disci- } \\
\text { nesia lingual }\end{array}$ & $\begin{array}{l}\text { Encefalopatía y crisis epilép- } \\
\text { ticas }\end{array}$ & $\begin{array}{l}\text { Autoinmune } \\
\text { Paraneoplásica 50\% }\end{array}$ \\
\hline Encefalitis antirreceptor AMPA & Ataxia & $\begin{array}{l}\text { Encefalopatía y crisis epilép- } \\
\text { ticas }\end{array}$ & $\begin{array}{l}\text { Autoinmune } \\
\text { Paraneoplásica } 65 \%\end{array}$ \\
\hline
\end{tabular}

HSV-1 = herpes virus $1, \mathrm{NB}=$ núcleos basales, TCSREM = trastorno de la conducta del sueño REM, VWN = virus West Nile, NMDA = N-metil-D-aspartato, GABA = Ácido gamma aminobutírico, AMPA $=\alpha$-amino-3-hidroxil-5-metil-4-isoxazol-propionato.

\section{DECLARACIÓN DE COMPROMISO ÉTICO}

Los autores confirmamos que para la publicación de este trabajo no fue necesaria la aprobación por parte del comité de ética e investigación institucional. El trabajo fue llevado a cabo con estricto apego a las normas éticas para investigación biomédica.

\section{CONSENTIMIENTO PARA PUBLICACIÓN}

Se obtuvo consentimiento informado por parte del paciente para la publicación de este reporte de caso.

\section{REFERENCIAS}

1. Venkatesan A, Geocadin RG. Diagnosis and management of acute encephalitis: a practical approach. Neurol Clin Pract. 2014; 4 (3): 206-215.

2. Solomon T, Michael BD, Smith PE, Sanderson F, Davies NW, Hart IJ et al. Management of suspected viral encephalitis in adults--Association of British Neurologists and British Infection Association National Guidelines. J Infect. 2012; 64 (4): 347-373.

3. Graus F, Titulaer MJ, Balu R, Benseler S, Bien CG, Cellucci T et al. A clinical approach to diagnosis of autoimmune encephalitis. Lancet Neurol. 2016; 15 (4): 391-404.

4. Gultekin SH, Rosenfeld MR, Voltz R, Eichen J, Posner JB, Dalmau J. Paraneoplastic limbic encephalitis: neurological symptoms, immunological findings and tumour association in 50 patients. Brain. 2000; 123 (Pt 7): 1481-1494.
5. Armangue T, Leypoldt F, Dalmau J. Autoimmune encephalitis as differential diagnosis of infectious encephalitis. Curr Opin Neurol. 2014; 27 (3): 361-368.

6. Serrano-Cardenas KM, Sánchez-Rodriguez A, Pozueta A, Pelayo $\mathrm{AL}$, Riancho J. Mesial encephalitis: an uncommon presentation of neurosyphilis: a case report and review of the literature. Neurol Sci. 2018; 39 (1): 173-176.

7. Zoccarato M, Valeggia S, Zuliani L, Gastaldi M, Mariotto S, Franciotta $\mathrm{D}$ et al. Conventional brain MRI features distinguishing limbic encephalitis from mesial temporal glioma. Neuroradiology. 2019; 61 (8): 853-860.

8. Adler AC, Kadimi S, Apaloo C, Marcu C. Herpes simplex encephalitis with two false-negative cerebrospinal fluid PCR tests and review of negative PCR results in the clinical setting. Case Rep Neurol. $2011 ; 3$ (2): 172-178.

9. Dalmau J, Gleichman AJ, Hughes EG, Rossi JE, Peng X, Lai M et al. Anti-NMDA-receptor encephalitis: case series and analysis of the effects of antibodies. Lancet Neurol. 2008; 7 (12): 1091-1098.

10. Baizabal-Carvallo JF, Jankovic J. Autoimmune and paraneoplastic movement disorders: an update. J Neurol Sci. 2018; 385: 175-184.

11. Bradshaw MJ, Venkatesan A. Herpes simplex virus-1 encephalitis in adults: pathophysiology, diagnosis, and management. Neurotherapeutics. 2016; 13 (3): 493-508. doi: 10.1007/s13311016-0433-7.

12. Lenka A, Kamat A, Mittal SO. Spectrum of movement disorders in patients with neuroinvasive west nile virus infection. Mov Disord Clin Pract. 2019; 6 (6): 426-433. doi: 10.1002/mdc3.12806.

13. Sarkari NB, Thacker AK, Barthwal SP, Mishra VK, Prapann S, Srivastava $D$ et al. Japanese encephalitis (JE). Part I: clinical profile of 1,282 adult acute cases of four epidemics. J Neurol. 2012; 259 (1): 47-57. 